tachycardia is sustained or recurrent, a VSDR using CPB is required. Later-aggravated atrioventricular block and residual shunt can occur, although at a low rate $(1.7 \%$ in our study).

PDCVSD has been applied for the past decade, but further studies at multiple centers to examine the longterm outcomes are required.

\section{CONCLUSIONS}

When VSD is indicated, PDCVSD is a safe modality with an acceptably mild early complication rate and a less severe late complication rate.

\section{References}

1. Hijazi ZM. Device closure of ventricular septal defects. Catheter Cardiovasc Interv. 2003;60:107-14

2. Bacha EA, Cao QL, Galantowicz ME, Cheatham JP, Fleishman CE, Weinstein SW, et al. Multicenter experience with perventricular device closure of muscular ventricular septal defects. Pediatr Cardiol. 2005;26:169-75.

3. Xing Q, Pan S, An Q, Zhang Z, Li J, Li F, et al. Minimally invasive perventricular device closure of perimembranous ventricular septal defect without cardiopulmonary bypass: multicenter experience and mid-term follow-up. J Thorac Cardiovasc Surg. 2010;139:1409-15.

4. Amin Z, Danford DA, Lof J, Duncan KF, Froemming S. Intraoperative device closure of perimembranous ventricular septal defects without cardiopulmonary bypass: preliminary results with the perventricular technique. $J$ Thorac Cardiovasc Surg. 2004;127:234-41.

5. Zhu D, Gan C, Li X, An Q, Luo S, Tang H, et al. Perventricular device closure of perimembranous ventricular septal defect in pediatric patients: technical and morphological considerations. Thorac Cardiovasc Surg. 2013;61:300-6.

\title{
Arterial switch operation for transposition of the great arteries with anomalies of cardiac situs and aortic position
}

\author{
Sachin Talwar, MCh, Aandrei Jivendra Jha, MS, Shiv Kumar Choudhary, MCh, \\ Palleti Rajashekar, MCh, and Balram Airan, MCh, New Delhi, India
}

\section{Supplemental material is available online.}

A prime determinant of successful outcome after the arterial switch operation (ASO) is an accurate transfer of coronary buttons to the neoaorta. ${ }^{1}$ Our experience with the ASO in patients with transposition of the great arteries and unusual relationship of the great arteries (levoposed aorta) and dextrocardia is presented here with details of appropriate modifications in surgical technique.

\section{MATERIALS AND METHODS}

Between January 2002 and January 2013, a series of 8 patients with transposition of the great arteries and either dextrocardia or aorta positioned anterior and to the left (levoposed aorta) underwent the ASO (Table 1). Of the 3 patients with dextrocardia, 1 patient had situs inversus totalis and the other 2 had normal visceral situs. Six patients, among them the patient with situs inversus totalis, had a levoposed aorta. Left-sided aortic arch was present in $50 \%$. Two patients had both coronaries arising from a single ostium from sinus 2. Five patients had the usual coronary anatomy for

From the Cardiothoracic Centre, All India Institute of Medical Sciences, New Delhi, India.

Disclosures: Authors have nothing to disclose with regard to commercial support.

Received for publication Feb 19, 2013; revisions received July 30, 2013; accepted for publication Aug 15, 2013; available ahead of print Oct 11, 2013.

Address for reprints: Sachin Talwar, MCh, Department of Cardiothoracic and Vascular Surgery, All India Institute of Medical Sciences, New Delhi 110029, India (E-mail: sachintalwar@hotmail.com).

J Thorac Cardiovasc Surg 2013;146:1553-6

$0022-5223 / \$ 36.00$

Copyright $\odot 2013$ by The American Association for Thoracic Surgery

http://dx.doi.org/10.1016/j.jtcvs.2013.08.052 transposition. Patient 7, who had situs inversus totalis with mirror-image dextrocardia, had a peculiar "double looping" coronary pattern with inverted origins of circumflex and right coronary arteries (a mirror image of the Yacoub type E coronary pattern). The Lecompte maneuver was carried out in 3 patients, including patient 7 . Juxtaposed right and left atrial appendages were present in 2 patients and 1 patient, respectively.

All patients underwent aortobicaval cannulation, and standard hypothermic $\left(28^{\circ} \mathrm{C}\right)$ cardiopulmonary bypass was instituted. The aorta and pulmonary artery were dissected free, and branch pulmonary arteries were completely mobilized. The ductus arteriosus was isolated, transfixed, and divided. The aorta was crossclamped, cold blood cardioplegia was delivered into the aortic root, and the heart was arrested. Transatrial ventricular septal defect closure was performed wherever needed, except in patients 5 and 7 , in whom closure was performed through the proximal neoaorta. The aorta was transected well above the sinotubular junction. Coronary buttons were harvested, and the main pulmonary artery (MPA) was divided at the confluence.

In all 5 cases of levocardia with levoposed aorta, the proximal right ventricular outflow tract (RVOT) was reconstructed first by suturing autologous pericardium to the margins of the defect created in the proximal aorta (neopulmonary artery) after harvesting of the coronary buttons. After RVOT reconstruction, a longitudinal wedge of tissue was excised from the proximal MPA (neoaorta), well above the sinuses, and the coronary button was sutured in place. Because of the peculiar situation in which the aorta was left-sided, the decision to perform the Lecompte maneuver was always postponed towards the end. Also it was anticipated that, the RVOT might impinge on the transferred coronary artery. To prevent this, the arteriotomy in the distal MPA was extended leftward. Starting from the center of the arteriotomy and up to its rightward end, the distal MPA was closed. The proximal MPA was then anastomosed to the under surface of the left pulmonary artery to shift the RVOT in a leftward direction, thus moving it away from the coronary button. If the Lecompte maneuver was not carried out, both the great arteries would come to lie parallel to each other (Figures 1 and 2).

In patients with dextroposed aorta where the aorta was situated to the right and anterior (patients 1 and 5), coronary buttons were transferred routinely and the Lecompte maneuver was performed. 
TABLE 1. Details of patients who had transposition of the great arteries with dextrocardia or with aorta anterior and to the left

\begin{tabular}{|c|c|c|c|c|c|c|c|c|c|c|c|}
\hline Case & Age & Sex & $\begin{array}{l}\text { Weight } \\
(\mathbf{k g})\end{array}$ & Anatomy & Surgery & $\begin{array}{l}\text { Coronary } \\
\text { pattern* }\end{array}$ & $\begin{array}{l}\text { CPB } \\
(\min )\end{array}$ & $\begin{array}{l}\text { Aoxc } \\
(\min )\end{array}$ & Lecompte & Outcome & $\begin{array}{c}\text { Follow-up } \\
(\mathrm{mo})\end{array}$ \\
\hline 1 & $1.5 \mathrm{mo}$ & M & 3 & $\begin{array}{l}\text { SS, DC }\{\mathrm{S}, \mathrm{L}, \mathrm{D}\} \text {, TGA, } \\
\text { ASD, SP VSD, severe } \\
\text { RPA stenosis, valvular } \\
\text { PS, JRAA, R arch Ao } \\
\text { R/A }\end{array}$ & $\begin{array}{l}\text { ASO, trans RA ASD } \\
\text { and VSD closure, } \\
\text { RPA plasty }\end{array}$ & $\begin{array}{l}\text { 2RLCx } \\
\text { (single } \\
\text { ostium) }\end{array}$ & 190 & 126 & No & $\begin{array}{l}\text { Died POD } 2 \\
\quad \text { (PHTN crisis) }\end{array}$ & - \\
\hline 2 & $3 \mathrm{~d}$ & M & 5 & $\begin{array}{l}\text { SS, LC }\{\mathrm{S}, \mathrm{D}, \mathrm{L}\}, \mathrm{TGA}, \\
\text { restrictive ASD, } \\
\text { P/BAS, IVS, JRAA, } \\
\text { R arch, Ao L/A }\end{array}$ & $\begin{array}{l}\text { ASO, trans RA ASD } \\
\text { closure }\end{array}$ & 2R1LCx & 116 & 90 & No & $\begin{array}{l}\text { Discharged } \\
\text { POD } 12\end{array}$ & 89 \\
\hline 3 & $8 \mathrm{mo}$ & $\mathrm{F}$ & 5 & $\begin{array}{l}\text { SS, LC }\{S, D, L\}, T G A, \\
\text { SP VSD, L arch, } \\
\text { Ao L/A }\end{array}$ & $\begin{array}{l}\text { ASO, trans RA VSD } \\
\text { closure }\end{array}$ & $\begin{array}{l}\text { 2RLCx } \\
\quad \text { (single } \\
\text { ostium) }\end{array}$ & 174 & 123 & No & $\begin{array}{l}\text { Discharged } \\
\text { POD } 10\end{array}$ & 10 \\
\hline 4 & $3 \mathrm{mo}$ & M & 4.5 & $\begin{array}{l}\text { SS, LC }\{\text { S, D, L }\}, \text { TGA, } \\
\text { VSD, PFO, JLAA, } \\
\text { R arch, Ao L/A }\end{array}$ & $\begin{array}{l}\text { ASO, trans RA VSD } \\
\text { closure }\end{array}$ & 2R1LCx & 116 & 100 & No & $\begin{array}{l}\text { Discharged } \\
\text { POD } 13\end{array}$ & 79 \\
\hline 5 & $6 \mathrm{mo}$ & F & 4.5 & $\begin{array}{r}\text { SS, DC }\{\mathrm{S}, \mathrm{L}, \mathrm{D}\}, \mathrm{TGA}, \\
\text { VSD, L arch, Ao R/A }\end{array}$ & $\begin{array}{l}\text { ASO and VSD closure } \\
\text { (through neoaorta) }\end{array}$ & 2R1LCx & 125 & 106 & Yes & $\begin{array}{l}\text { Discharged } \\
\text { POD } 12\end{array}$ & 68 \\
\hline 6 & $18 \mathrm{mo}$ & M & 5 & $\begin{array}{l}\text { SS, LC }\{\mathrm{S}, \mathrm{D}, \mathrm{L}\} \mathrm{TGA}, \\
\text { large ASD, VSD, } \\
\text { JRAA, L arch, Ao L/A }\end{array}$ & $\begin{array}{l}\text { ASO, ASD and VSD } \\
\text { closure }\end{array}$ & 2R1LCx & 138 & 116 & No & $\begin{array}{l}\text { Died postop, } \\
\text { ECMO, VF } \\
\text { on POD2 }\end{array}$ & - \\
\hline 7 & $5 \mathrm{mo}$ & M & 5 & $\begin{array}{l}\text { SI, DC }\{\text { I, L, L }\}, \text { TGA, } \\
\text { ASD, VSD, R arch, } \\
\text { Ao L/A }\end{array}$ & $\begin{array}{l}\text { ASO, ASD and VSD } \\
\text { closure (through } \\
\text { neoaorta) }\end{array}$ & 1LR2Cx & 116 & 96 & Yes & $\begin{array}{l}\text { Discharged } \\
\text { POD } 13\end{array}$ & 64 \\
\hline 8 & $2.5 \mathrm{mo}$ & M & 4 & $\begin{array}{c}\text { SS, LC }\{\mathrm{S}, \mathrm{D}, \mathrm{L}\} \mathrm{TGA} \\
\text { levoposed aorta, VSD, } \\
\text { ASD, L arch, Ao L/A }\end{array}$ & $\begin{array}{l}\text { ASO, ASD and trans } \\
\text { RA VSD closure, } \\
\text { supportive CPB for } \\
30 \text { min (borderline LV) }\end{array}$ & 2R1LCx & $167 \dagger$ & 84 & No & $\begin{array}{l}\text { Discharged } \\
\text { POD } 12\end{array}$ & 2 \\
\hline
\end{tabular}

$\overline{C P B}$, Cardiopulmonary bypass time; $A o x c$, aortic crossclamp; $S S$, situs solitus; $D C$, dextrocardia; $T G A$, transposition of the great arteries; $A S D$, atrial septal defect; $S P$, subpulmonic; VSD, ventricular septal defect; $R P A$, right pulmonary artery; $P S$, pulmonary stenosis; $J R A A$, juxtaposed right atrial appendages; $R$, right; $A o$, aorta; $R / A$, right and anterior; $A S O$, arterial switch operation; $R A$, right atrium; $P O D$, postoperative day; $P H T N$, pulmonary hypertension; $L C$, levocardia; $P / B A S$, post-balloon atrial septostomy; $I V S$, intact ventricular septum; $L A$, left and anterior; $L$, left; $P F O$, patent foramen ovale; $J L A A$, juxtaposed left atrial appendages; postop, postoperatively; $E C M O$, extracorporeal membrane oxygenation; $V F$, ventricular fibrillation; $S I$, situs inversus; $L V$, left ventricle; $F$, female; $M$, male. *Two patients had both coronaries arising from a single ostium from sinus 2 $(2 R L C x)$. Five patients had the usual coronary anatomy for transposition $(2 R 1 L C x)$. Patient 7 had a peculiar "double looping" coronary pattern with inverted origins of circumflex and right coronary artery $(1 L R 2 C x)$. $\dagger$ Total represents $97 \mathrm{~min}$ plus an additional $70 \mathrm{~min}$ of supportive bypass.

Patient 7 (case published elsewhere previously ${ }^{2}$ ) had an extremely unusual $\{\mathrm{I}, \mathrm{L}, \mathrm{L}\}$ configuration, with mirror-image dextrocardia with inverted origin of the circumflex and right coronary arteries. A conduit-lengthening procedure was therefore needed. The left coronary button was harvested with a longer "tongue" of native aortic tissue attached distal to the coronary origin. A flap with dimensions similar to this button was created in the neoaorta, and the anastomosis was made such that the native aortic flap was placed superior to the neoaortic flap (Figure E1). The remainder of the operation was as usual.

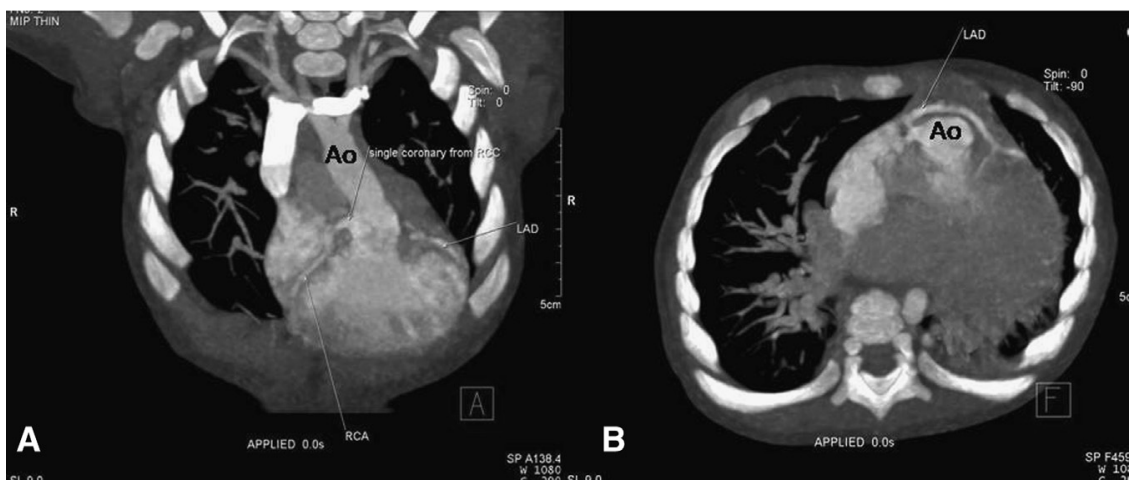

FIGURE 1. Computed tomographic angiography of patient 3 shows the anterior and left-sided aorta (Ao) with a single coronary artery. A, Maximum intensity projection $(M I P)$ reformatted image in coronal plane. B, MIP reformatted image in axial oblique plane. RCC, Right coronary cusp; $L A D$, left anterior descending coronary artery; $R C A$, right coronary artery. 

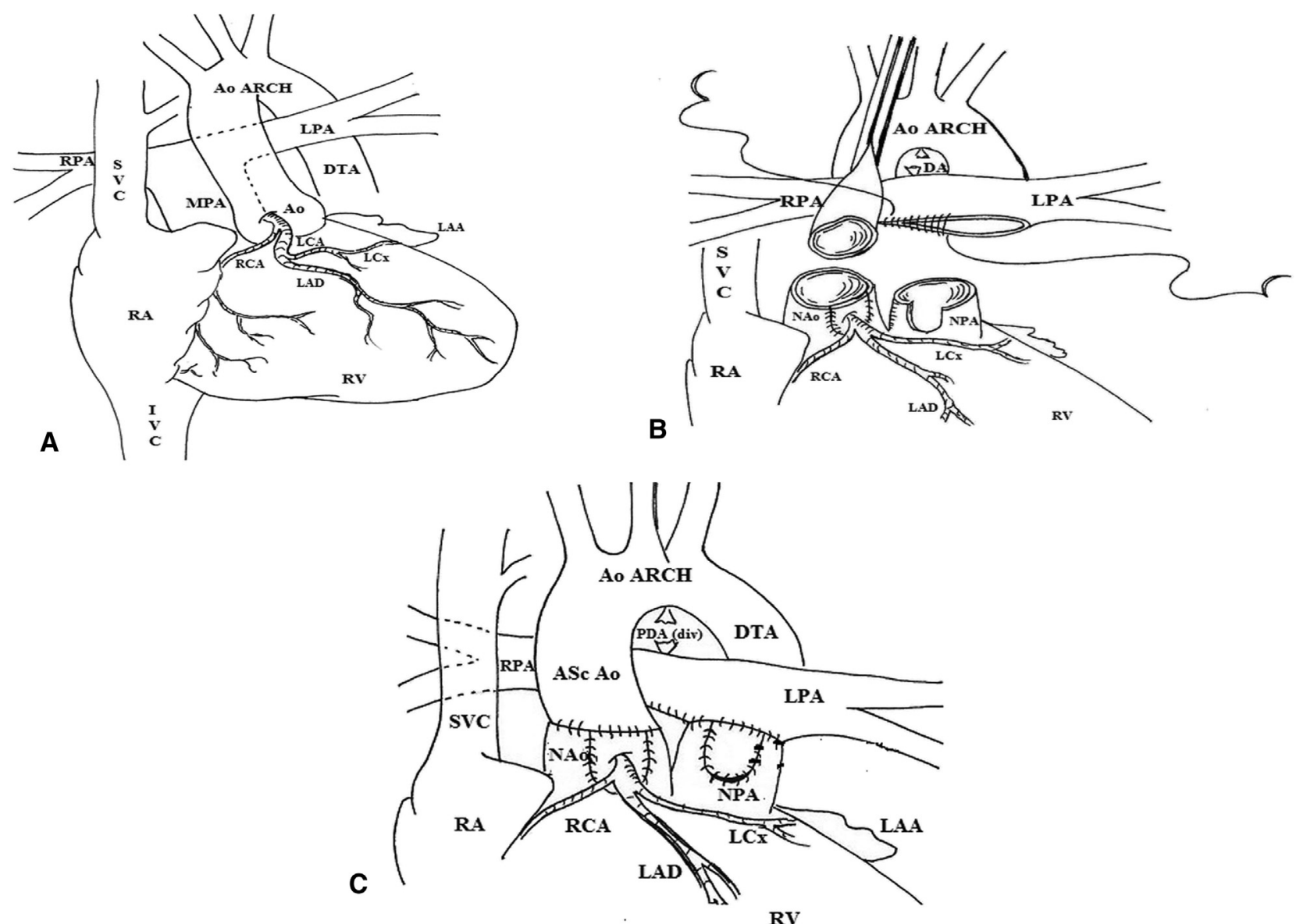

FIGURE 2. Surgical technique adopted in patient 3. A, External cardiac anatomy. B, The coronary button has been transferred. The main pulmonary artery $(M P A)$ is being closed up to the right pulmonary artery $(R P A)$ after extending the arteriotomy into the left pulmonary artery $(L P A)$. C, Final reconstruction. Note that the Lecompte maneuver has not been performed. Ao ARCH, Aortic arch; SVC, superior vena cava; DTA, descending thoracic aorta; $A o$, aorta; $L C A$, left coronary artery; $L A A$, left atrial appendage; $R C A$, right coronary artery; $L C x$, left circumflex coronary artery; $L A D$, left anterior descending coronary artery; $R A$, right atrium; $R V$, right ventricle; $I V C$, inferior vena cava; $D A$, ductus arteriosus (divided); $N A o$, neoaorta; $N P A$, neo-pulmonary artery; $P D A$, patent ductus arteriosus; $A S C A o$, ascending aorta.

Aortic crossclamp time ranged from 84 to 126 minutes (median, 103 minutes). Total cardiopulmonary bypass time ranged from 97 to 190 minutes (median, 131 minutes).

\section{RESULTS}

There were two early deaths. Patient 1 died on the second postoperative day, 2 hours after extubation because of a refractory pulmonary hypertensive crisis. His postoperative echocardiogram before extubation had demonstrated normal biventricular function and normal flow into the coronary arteries. Patient 6 had low cardiac output in the immediate postoperative period. Transthoracic echocardiography showed a poorly contracting left ventricle, normal flow into the proximal coronaries, and no residual defect. Electrocardiography showed no evidence of ischemia. Extracorporeal membrane oxygenation was promptly instituted; however, he could not be successfully weaned. Parents of both patients were counseled regarding autopsy, but they denied consent.
Patient 8 had a borderline left ventricle and required supportive cardiopulmonary bypass for an extra 70 minutes. Subsequent recovery was normal. The median hospital stay of the 6 survivors was 12 days. Postoperative echocardiography at discharge showed normal biventricular function and normally flowing coronary arteries.

Follow-up of the 6 survivors ranged from 2 to 89 months (median, 66 months). At last follow-up, these patients are receiving no cardiac medication and have normal biventricular function on echocardiography.

\section{DISCUSSION}

In visceroatrial situs solitus with complete transposition, the aorta is right-sided and anterior, whereas an anterior and left-sided aorta occurs in corrected transposition. A rare but important exception to this rule occurs when in patients with visceroatrial situs solitus and complete transposition the aorta lies to the left and anterior, described 
as complete transposition $\{\mathrm{S}, \mathrm{D}, \mathrm{L}\}$ instead of the usual expected form of complete transposition $\{S, D, D\}$. Houyel and colleagues ${ }^{3}$ studied 26 such patients (16 surgical and 10 postmortem studies) and found that increasing degrees of levorotation of the subaortic infundibulum and aortic valve in these cases increased the probability of other associated anomalies: subaortic ventricular septal defect, pulmonary outflow tract stenosis, and conal septal hypoplasia.

In many of these patients $\{\mathrm{S}, \mathrm{D}, \mathrm{L}\}$, the great arteries may not be side to side, and the leftward position of the aorta may be minimal. It is also extremely rare for the aortic annulus to be located completely to the left of the pulmonary annulus, and more often than not the anomaly is just an abnormal course of the aorta and the pulmonary artery trunks. In such situations, the coronary artery anatomy may be complex and require surgical innovation to achieve a successful coronary transfer.

While performing the ASO in such situations, we have found the following to be helpful: (1) High aortic transection, well above the sinotubular junctions, allows a longer coronary button and coronary prolongation. (2) Transection of the MPA right at the bifurcation is helpful for a similar reason and also allows the coronary button to be placed well above the sinotubular junction, thus avoiding distortion of the neoaortic root. (3) Reconstruction of the proximal
RVOT before coronary button transfer is often helpful, because the right and to some extent the anterior aspects of this suture line often lie under the implanted coronary buttons, making suturing in this area difficult after reimplantation of the coronary buttons. (4) Shifting of the RVOT on one of the pulmonary arteries while closing the MPA directly or with a patch minimizes the risk of coronary artery compression by a dilated pulmonary artery. (5) Individually assessing the need for a Lecompte maneuver in each patient and performing this maneuver as a final step helps to assess the final positioning of the coronaries and great arteries with respect to each other. In our experience, in patients with levoposed aorta, it may be best to avoid the Lecompte maneuver.

\section{References}

1. Wernovsky G, Mayer JE Jr, Jonas RA, Hanley FL, Blackstone EH, Kirklin JW, et al. Factors influencing early and late outcome of the arterial switch operation for transposition of the great arteries. J Thorac Cardiovasc Surg. 1995;109:289-302.

2. Talwar S, Shivaprasad BM, Kothari SS, Choudhary SK. A novel conduitlengthening technique to facilitate the arterial switch operation in an infant with a problematic combination of coronary anomalies. Tex Heart Inst J. 2009;36:234-7.

3. Houyel L, Van Praagh R, Lacour-Gayet F, Serraf A, Petit J, Bruniaux J, et al. Surgery for congenital heart disease: transposition of great arteries $\{S, D, L\}$. Pathologic anatomy, diagnosis, and surgical management of a newly recognized complex. J Thorac Cardiovasc Surg. 1995;110:613-24. 

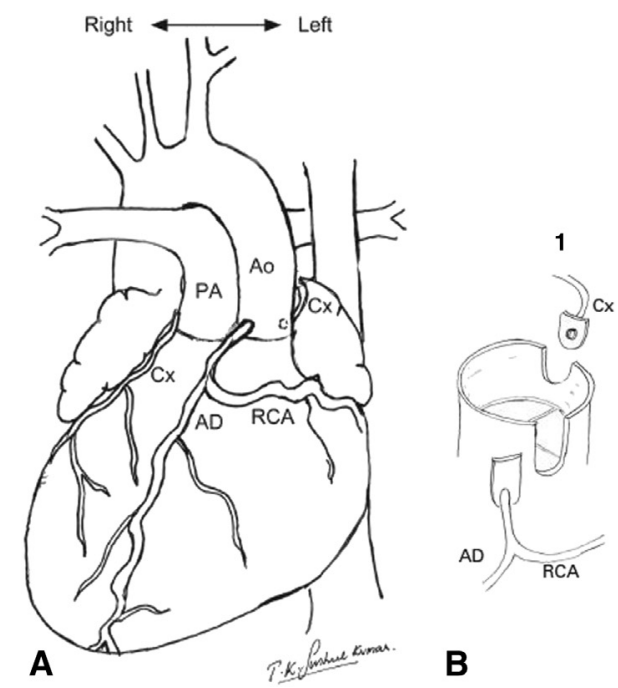

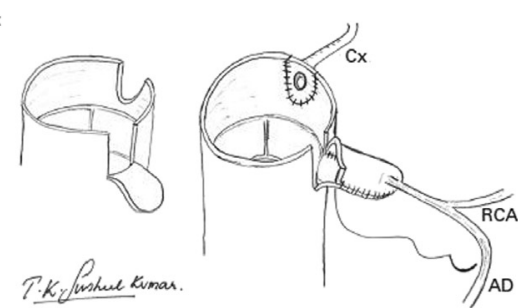

FIGURE E1. Anatomic and technical details of patient 7, previously published elsewhere. ${ }^{2}$ A, This drawing of the external cardiac anatomy shows dextrocardia, transposition of the great arteries, and the origin and distribution of the coronary arteries. Note that the left coronary artery, arising from the right- and anterior-facing sinus, bifurcates into an anterior descending coronary artery $(A D)$ and a right coronary artery $(R C A)$. The right coronary artery then loops in front of the right ventricular outflow tract to descend into the atrioventricular groove on the left side. The circumflex coronary artery $(C x)$ originates from the left anterior sinus and takes a posterior and leftward course before finally turning to the right and looping behind the pulmonary artery $(P A)$ to reach the right side of the atrioventricular groove. B, Steps of coronary artery transfer: (1) Coronary buttons are harvested. Note that the button bearing the left coronary artery—which bifurcates into the anterior descending coronary artery and the right coronary artery—has been harvested together with a segment of aortic (Ao) wall that extends well above the ostium. (2) A flap is created from the neoaorta. (3) Flaps are sutured in preparation for anastomosis of the neoaorta to the distal aorta, which will complete the coronary transfer. Reproduced with permission from Talwar S, Shivaprasad BM, Kothari SS, Choudhary SK. A novel conduit-lengthening technique to facilitate the arterial switch operation in an infant with a problematic combination of coronary anomalies. Tex Heart Inst J. 2009;36:234-7. Copyright 2009, Texas Heart Institute, Houston, Tex. 